\title{
Investigating the Occupants' Behaviors and Perceptions Concerning the Sustainable Transportation System in Tehran City
}

\author{
Hashem HashemNejad (Corresponding author) \\ Associate Professor, Department of Architecture \\ University of Science and Technology, Tehran, Iran \\ Mohsen Feyzi \\ Associate Professor, Department of Architecture \\ University of Science and Technology, Tehran, Iran \\ Morteza Sedigh \\ $\mathrm{PhD}$ candidate, Department of Architecture \\ University of Science and Technology, Tehran, Iran \\ E-mail: Morteza.Seddigh@yahoo.com
}

\begin{abstract}
A transport crisis of major proportions is looming on the horizon in many of the world's cities. Road travel speeds during peak hours have already fallen below that of horse-drawn carriages, popular 80 years ago. Increasing motorization and air pollution threaten economic development as well as the environment. However, opportunities exist to solve these problems by limiting the demand for transport without affecting socioeconomic development. An efficient and equitable urban transport policy can achieve its objectives by using a combination of new investment, economic incentives as well as adequate planning and regulatory measures. This will reduce overall travel and ensure the travel that occurs is safe, efficient and environmentally sustainable, as it will be discussed in this article.

This paper investigates how sustainable transportation concerns systems, policies, and technologies and also its aims for the efficient transit of goods and services, and sustainable freight and delivery systems. The results show that there are important key issues in sustainable transportation such as Access not mobility; Moving people not cars; Reclaim city space for walking and pedaled vehicles and Stop subsidizing private motor vehicle. Besides the design of vehicle-free city planning, along with pedestrian and bicycle friendly design of neighborhoods is a critical aspect for grassroots activities.
\end{abstract}

Keywords: Green City, Environment, Sustainability, Occupants' Demands, Transportation

\section{Introduction}

A sustainable transportation system has been defined as one that satisfies current transport and mobility needs without compromising the ability of future generations to meet their own (Black, 1997; Richardson, 1999). Other authors have written about the emergence of new goals for transportation decision-making and for mainstreaming alternative practices by retrofitting existing networks and creating healthier communities (Dittmar, 1995; Newman, 1998). On urban grounds sustainable transportation planning can be seen as providing incentives for walking, bicycling, taking mass transit, ridesharing, discouraging the use of single-occupancy cars by passing on the full costs of parking to drivers, and linking transportation planning to land-use planning.

Tehran city (the capital of Iran) has an extremely high automobile dependence. Automobiles not only are the focus of transportation systems but they very often push the planning decision making processes It is extensively accepted that trends in motorization on urban spaces equate those experienced by society at large. In the last decade, city planners have struggled to provide access and mobility without destroying streets qualities as distinct part of the cities. Due to federal requirements concerning air quality, increasing congestion, lack of land for parking, the high cost of constructing parking structures, pressures to reduce traffic's impact on surrounding neighborhoods, and constraints on financial resources, many cities are exploring a range of environmentally appealing solutions to alleviate congestion and improve safety for all citizens (Poinsatte and Toor, 2001). Many of these solutions are based on the concept of transportation demand management (TDM), which include market prices for parking, expanded transit access, park and ride lots complemented by bus shuttles, rideshare programs, bicycle and pedestrian facilities and traffic-calming schemes, among others. This paper is guided by one major research question: How have urban spaces especially main streets encouraged a modal shift from cars to other modes, in particular to bicycling and walking; its main purpose is to reflect on the opportunity to create sustainable city from a bicycle and pedestrian planning viewpoint. This paper attempts to answer the call for more research on ways to create more sustainable communities (Litman, 1999; Taylor and Davis, 1999), and on the links between transport use and activity patterns (Preston, 2001). This research is based on the results of a survey of eight bicycle and pedestrian friendly urban streets. The first part of this paper discusses how changes in 
transportation patterns can affect city planning and community life. The second part presents the research methods and introduces the transportation patterns at the eight urban streets. The third part discusses the survey results. Finally, the last part gives some concluding comments.

\section{Sustainable Transportation and TDM Planning}

The need to plan for sustainable transport is evident. Global warming poses significant challenges for cities. The transport sector alone, according to the World Resources Institute (2005), accounts for 24.1\% of CO2 emissions worldwide, yet its importance in local commuting, linking the global system of cities, and stimulating economic interactions is crucial. "The solution" for keeping up international, national, regional, and local interactions while fostering sustainable development has yet to be found; no strategy for sustainable transportation systems agreed to by all stakeholders across countries so far exists. Sustainability and sustainable development have been the main theme of many international conferences, such the UN Rio de Janeiro 1992 Earth Summit, the 1995 European Conference of Ministers of Transport, and the 1997 Kyoto Convention on Climate Change. The origins of the concept of sustainability date back to the early seventies, but the most often cited definition of sustainable development was stated by the World Commission on Environment and Development in its so-called "Brundtland Report" (1987, p. 54). This report defines sustainable development as "development that meets the needs of the present without compromising the ability of future generations to meet their own needs. "Given that this sustainability definition was fairly broad, governments across the world sought to refine it in terms more applicable to their own situations, yet closely aligned with the Brundtland definition. Most such definitions had in common the three dimensions of sustainability: economic, social, and environmental. Sustainable solutions should be economically viable, socially equitable and ethically responsible, and consistent with the long-term ecological balance of the natural environment. While the urgency of planning for sustainability has increased over the years, concrete solutions accepted internationally have been slow to emerge. Each country is constrained by its individual setting and hence faces unique hurdles in moving towards sustainability. Despite these hurdles and other international challenges, moves towards sustainable development are evident, as this Projections volume highlights. Across the globe researchers are seeking to develop, and cities are trying to implement, sustainable policies. Planning for sustainable transportation systems is a complex task that involves multiple options and uncertainties. Government seeks an optimal package of policies that is willingly accepted by all affected groups. An ideal implementation strategy would allow for easy transition from the way people formerly travelled to the new system. Finally, the actual impact of the policy package and travelers' responses need ongoing monitoring to insure that the policies' implementation is meeting desired goals. Urban streets can constitute a laboratory for testing and implementing various alternative transportation strategies, reducing infrastructure costs and minimizing their impacts on surrounding areas. One aspect often overlooked by city administrators and planners is the city's potential to affect not only the transportation behavior of the citizens in the present but also the transportation habits and the environmental awareness that people can develop in the long term, as "they will progress to occupy influential roles in government, companies or other organizations" (Tolley, 1996, p. 214). However, since occupants are more open-minded and have the potential to become 'movers and shakers' if properly motivated, they can become powerful forces for the establishment of bicycle and pedestrian friendly communities (Weerts, 1992). Bicycling and walking are two components of more global TDM strategies. In fact, TDM can be defined as a package of planning strategies, incentives and disincentives, which emphasize alternatives to single occupant vehicle traveling (see CUTR, 1996; Meyer, 1999; Ewing, 1999). TDM includes not only traffic engineering such as trafficcalming schemes, but also multimodal solutions. The most widely implemented solutions are parking management, carsharing, park and ride schemes, mass transit, vehicle technology and alternative fuels, and the use of the internet and video to provide online classes and transportation information (Markowitz and Estrella, 1998). Car-based transportation has many hidden costs (Balsas, 2001). It is expensive and inefficient over short distances and is a major contributor to global warming. The major problem with auto mobility, however, is the amount of parking it requires (Shoup, 1997; Dober, 2000). Planning laws require parking minimums, which very often make it expensive to build. Shoup (1997) has argued that eliminating minimum parking requirements and free parking would substantially reduce the cost of urban development, improve urban design and reduce automobile dependency, and restrain urban sprawl. On city streets parking is a common problem with different slants. Municipalities are also working in collaboration with transit agencies across the country to provide innovative transit pass programs. For instance, free transit passes are being funded with citizen's fees or through innovative partnerships with local municipalities. This has become known as 'Unlimited Access'. It not only reduces the demand for parking, increases citizens' access to housing and employment, helps government recruit and retain occupants, but also increases transportation equity (Brown et al., 2001, p. 235). In order to reverse transit's negative image, transportation agencies are decreasing headways and increasing service amenities such as providing passengers with real time schedule information through Intelligent Transportation Systems. A truly integrated TDM program may bring many environmental and societal benefits by enhancing the use of existing transportation systems. If fewer cars are traveling to urban spaces, then fewer parking spaces are required, lower maintenance costs are incurred, and the land currently used for parking can be converted to other, more rewarding uses such as open space or new environmentally sound research buildings. This can only happen if, in addition to a comprehensive approach to promote alternative 
transportation modes, car use is restrained or charged at full cost and the funds redistributed to improve those alternative options (Tolley, 1996).

\section{Complementary Modes of Transportation}

Walking and bicycling are complementary modes of transportation to get around urban streets. As Weerts (1992) recognizes bicycling is often seen as the 'poor step-child' of other alternative modes; however, bicycling and walking have evolved from being the 'forgotten modes' to emblems of a high quality of life (Wilkinson, 1997; Clarke, 2000). In recent years more bicycles have been sold annually than automobiles, with total bicycle ownership in 1999 at over 120 million units in the United States (Dober, 2000). Bicycling and walking increased their visibility with the ISTEA legislation in the beginning of the 1990s. As Clarke (1997, p. 340) puts it, "the simple mention of bicycling and walking throughout the legislation has helped to legitimize these modes and make them an acceptable activity for transportation agencies to include in their regular operations". Federal funding also increased substantially in the last decade and pedestrian and bicycle safety at the USDOT has become a priority. At many colleges a high percentage of students live on campus, and another considerable percentage of students and staff live within a reasonable walking and cycling distance. The bicycle offers riders speed and flexibility over short distances. It produces no pollution, uses no energy, is silent, can be accommodated with relatively little space, is fast and cheap, and is also accessible to many people who cannot drive, especially the young (Tolley, 1996, p. 215). On some campuses biking is deeply rooted in local culture. On the other hand, walking is the primary mode of transportation for many people, although few of us may realize how it is a big part of our trip (Blomberg et al., 2000). Walking is fast, direct, and has no costs involved. In addition, these two modes have many health benefits.

Despite the fact that not everyone can use bicycles, the problem is that growing levels of auto mobility have catered more to the car than to these two modes. On urban spaces, walking is affected by safety concerns at intersections, when pedestrians must cross roadways used by motor traffic and bicycles, or walk along improperly build or maintained corridors. Comfort is a characteristic that can encourage more walking. Examples range from protection from the weather and good illumination, to visual appearance and amenities (litter containers, benches, etc.). Despite the Americans with disabilities act (ADA) of 1990, which requires transportation systems to offer equal access to disabled people, the disabled still have problems with stairs, narrow passageways, long distances, slippery surfaces and poor-illuminated areas. The need to provide parking lots in close proximity to buildings also contributes to unfriendly land use development and long walking distance between locations, which can increase the fear of assault, especially after dark or when there are few others around. Regarding bicycling, many governments lack proper and adequate bicycle facilities, including bicycle paths and lanes, intersection treatments, signage and parking. Many times bicycling on campus can be dangerous. Accidents can occur because of speeding, mixing types of traffic, poor right-of-way design, and college-age youth's propensity to ride outside the routes designated for bicycles and to ignore traffic rules and regulations (Dober, 2000). Because bicycles are not considered as 'design vehicles', in many of the cases engineers have not considered the special needs of bicyclists on their precincts (Schimeck, 1996). The lack of secure bicycle parking increases the possibilities for bicycle theft, which at the same time acts as a major deterrent to bicycle use. On the other hand, many bicyclists are accused of not obeying the rules of the road. This can cause resentment towards cyclists among other road users, which can cause accidents. One way to solve this problem is to combine education and enforcement programs to help bicyclists ride safely and other users to share the road with them. Nelson and Allen (1997) have argued that there is a latent demand for bicycle facilities that can only be tapped by providing those facilities. On the other hand, Pendakur et al., 1995 claim that when the many benefits of nonmotorized modes are considered it makes sense to promote them as much as possible.

\section{Analyzing the Transportation Patterns in Case Studies}

For survey research, eight bicycle and pedestrian friendly urban streets in Tehran city are selected. These streets are: 1- Vali -Asr Street -2- Niavaran Street -3- Darband Street -4- Dar-Abad Street -5- Pirouzan Street -6Lavizan Street -7- Asad- Abadi Street -8- Keshavarz Boulevard. The criteria used in the selection was three-fold: (1) bicycling and walking as part of a larger TDM program, (2) known bicycle and walking levels and existence of well publicized nonmotorized planning proactivity, and (3) expedite access to up-to-date and accurate information. This research is mainly based on a survey and on several semi-structured interviews with campus and transportation planners and TDM coordinators at the eight Tehran streets. The survey was designed based on the National Bicycling and Walking Study's chapter on Actions Plans and Programs at the local level (USDOT, 1994); and it was administered during the April 2010. Table 1 provides contextual information about the eight streets. Although data on bicycle commuting is scarce and few statistics are available (Moritz, 1997). The chosen streets are necessarily different and face different challenges as a consequence of their respective locations, such as weather and terrain, total population, area, budget constraints, historical administration, and programs in place. Modal shares are also dependent upon street bicycle facilities and, probably most important of all, the existence of a local bicycle culture.

Table 2 shows the organizational aspects regarding nonmotorized transportation. Six of the eight streets have bicycle and pedestrian committees; the other two streets only have transportation advisory committees. The 
advantage of having a specific bicycle committee is that bicyclist's interests have more possibilities of being considered in the transportation planning process. It is important to have citizens in the committee since many times citizens are the ones asking urban street administrators to make the settings of their trainings more sustainable. Also local user groups have a very important role in monitoring and revising city sustainable transportation policies. Four streets currently have a full time bicycle and pedestrian coordinator. In general, his responsibilities are assessing needs, identifying opportunities, formulating and implementing plans, coordinating events and maintaining the campus bicycle and pedestrian facilities. Urban streets with bicycle committees and coordinators tend to conduct surveys more often and to attract more funding. Funding is needed to fund bicycle facilities such as paths, lanes, parking racks and lockers, and to pay a bicycle coordinator. Revenues may come bicycle registration fees and fines for traffic and parking violations but also from foundations, alumni associations, state and federal sources. Another area of intervention for the committee and the coordinator is the communication of transportation practices with the urban streets and with the surrounding communities. Accordingly to the survey respondents, all citizens undertake this practice to a certain extent. The advantages of having a bicycle committee and a bicycle coordinator include the ability to make changes to existing policies more expeditiously. Nonmotorized traveling can only be maximized by thoroughly integrating bicycling and walking needs and desirable circulation patterns in all transportation, and housing and environmental policies. It is important to make nonmotorized traveling compatible with land-uses and to establish linkages between the different elements of the transportation system on urban streets and in the surrounding communities. On urban streets it is important to institutionalize TDM policies in the planning routines of the city and to incorporate city-wide nonmotorized urban design guidelines with site and master planning. For instance, bicycle storage rooms and shower facilities should be accommodated in new buildings, and corridors for greenways or walkways that represent desirable lines of travel should be reserved. Finally, it is also important to integrate and coordinate planning efforts with the surrounding communities. Table 3 shows that these aspects are reasonably well taken into consideration in the planning processes at the eight cases. Although walking and bicycling can take advantage of complementary planning strategies, it is important to separately consider the needs of the two groups in order to reduce modal conflicts (Untermann, 1984). Pedestrians' facilities include a network of sidewalks and dedicated zones. Regarding bicyclists McClintock (1992) argues that special facilities can offer important contributions to improving bicyclists' safety but only if they offer some distinct advantages to cyclists, in terms of safety, convenience, comfort, directness, and general attractiveness. Despite the need to make every road cycle able, a logical and well-identified bicycle network composed of different types of bikeways should be implemented with identifiable links to off-campus facilities (Huang and Ye, 1995). The selected case studies show a variety of bicycle facilities (Table 4). Where pedestrians share the space with bicyclists it is important to implement a dismount zone policy. All streets in the research reported to have dismount zones and pedestrians only precincts. Dar- Abad Street has 1.5 miles of roadway from which all motor traffic is prohibited except service, delivery and emergency vehicles. In four streets traffic-calming measures are also being implemented. Proper facility maintenance and bicycle parking are aspects of the bicycle network that cannot be overlooked. Bicycle theft on urban street can be a major deterrent to bicycle use as well, thus secure bicycle-parking racks and lockers are required. Five of the eight cases reported having bicycle lockers for rent in their precincts.

The purpose of this paper was to understand what could be done to make urban spaces more sustainable communities from the bicycle and pedestrian planning point of view. A survey of 8 urban streets showed some of the best practices. Fig. 1 shows the importance of non motorized transportation in the selected cases. Fig. 2 shows a much more balanced and equitable modal share when compared with the national ratio.

\section{Conclusion}

The key finding is that urban streets are clearly 'de-marketing automobile commuting and actively promoting alternative transportation modes. In order to create more bicycle and walking friendly urban spaces efforts need to focus on the following seven measures: TDM strategies, organization, planning, facilities, promotion, education, and enforcement. Although these measures need to be tailored to local conditions, they should not be implemented alone because only the developments of highly integrated strategies have the potential to improve sustainability.

The implementation of the lessons learned in this research is likely to 'encounter considerable opposition' which is a normal part of the process of change. One cannot expect swift changes, since 'the extent of what is possible and realistic will change over time as costs rise, technology changes, and awareness and understanding increase. However, municipalities have the possibility to take a leadership role and promote environmentally sound programs. The need and opportunities for additional research, teaching and service learning on non motorized travel are countless. They are bounded only by our creativity and willingness to take risks and improve our way of living. The overriding issue is the way of thinking and the need to change routine decisions, levels of commitment and one's own behavior. Nonetheless, as Weerts recognized so well a decade ago, those looking for solutions to worsening air quality, traffic, and parking problems, may well find the resources, expertise and enthusiasm to establish workable bicycle programs right in their midst-at their local institutions of higher learning. 


\section{References}

Balsas, C. (2001). Cities, cars and sustainability. Urban Affairs Review. 36 (3), 429-432.

Balsas, C. (2002). New directions for bicycle and pedestrian planning in the US. Planning Practice and Research. 17 (1), 91-105.

Black, W. (1997). North American transportation: perspectives on research needs and sustainable transportation. Journal of Transport Geography. 5 (1), 12-19.

Brown, J., Hess, D., Shoup, D. (2001). Unlimited access. Transportation. 28, 233-267.

Carter, C. (1996). A campus transportation alternative revisited. Transportation Quarterly. 50 (3), $123-129$.

Checkoway, B. (1997). Reinventing the research university for public service. Journal of Planning Literature. 11 (3), 307-319.

Clarke, A. (1997). Green modes and ISTEA in the United States. In: Tolley, R., (Ed.), The Greening of Urban Transport, 2nd ed, Wiley, New York.

Clarke, A. (2000). Bicycling, pathway to the future-TRB Millennium papers: committee on bicycling (available at http://www. nationalacademies.org/trb/publications/millennium.)

CUTR. (1996). Commute Alternatives Systems Handbook, Author, Tallahassee.

Dittmar, H. (1995). A broader context for transportation planning, not just an end in itself. Journal of the American Planning Association. 61 (1), 7-13.

Dober, R. (2000). Campus Landscape, Wiley, New York.

Dulken, D. (1992). The very model of a suburban community, what we can learn from the university campus. Planning. 58 (8), 24-25.

Engwicht, D. (1993). Reclaiming Our Cities and Towns, New Society Publishers, Philadelphia.

Ewing, R. (1999). Traffic-Calming State of the Practice, Institute of Transportation Engineers, Washington, DC.

Farris, M., Radwan, A. (1989). A campus transportation alternative. Transportation Quarterly. 43 (1), 89-99.

Forester, J. (1994). Bicycle Transportation, 2nd ed, MIT Press, Cambridge.

Forester, J. (2001). The bicycle transportation controversy. Transportation Quarterly. 55 (2), 7-17.

Gardner, G. (1998). When cities take bicycles seriously. World-Watch. 11 (5), 16-23.

Griffen, W. (2000). Envisioning a different civilization: education's next goal. Educational Studies. 31 (4), 411-420.

Hanson, S., Hanson, P. (1976). Problems in integrating bicycle transportation into the transportation planning process. Transportation Research Record. 570, 24-30.

Huang, Y., Ye, G. (1995). Selecting bicycle commuting routes using GIS. Berkeley Planning Journal 10, 75-90. Litman, T. (1999). Exploring the paradigm shifts needed to reconcile transportation and sustainability objectives. Transportation Research Record. 1670, 8-12.

Litman, T. (2001). Campus Trip Reduction-TDM Encyclopedia (available at http://www.vtpi.org/).

Mansfield, W. (1998). Taking the university to task. World-Watch May- June, 24-30.

Markowitz, F., Estrella, A. (1998). Campus moves. Planning. 64 (7), 14-18.

McClintock, H. (Ed.). (1992). The Bicycle and City Traffic, Principles and Practice, Belhaven Press, London.

Meyer, M. (1999). Demand management as an element of transportation policy: using carrots and sticks to influence travel behavior. Transportation Research Part A. 33, 575-599.

Moritz, W. (1997). Survey of North American bicycle commuters-design and aggregate results. Transportation Research Record. 1578, 91-101.

Nelson, A., Allen, D. (1997). If you build them, commuters will use them, association between bicycle facilities and bicycle commuting. Transportation Research Record. 1578, 79-83.

Newman, P. (1998). From symbolic gesture to the main street: next steps in local urban sustainability. Local Environment. 3 (3), 299-311.

Newman, P., Kenworthy, J. (1999). Sustainability and Cities-Overcoming Automobile Dependence, Island Press, Washington, DC.

Pendakur, V., Badami, M., Lin, Y. (1995). Nonmotorized transportation equivalents in urban transport planning. Transportation Research Record. 1487, 49-55.

Poinsatte, F., Toor, W. (2001). Finding a New Way: Campus Transportation for the 21st Century, 2nd ed, University of Colorado, Boulder. 
Potter, S., Skinner, M. (2000). On transport integration: a contribution to better understanding. Futures. 32, 275-287.

Preston, J. (2001). Integrating transport with socio-economic activity-a research agenda for the new millennium. Journal of Transport Geography. 9 (1), 13-24.

Priemus, H. (1995). Reduction of car use: instruments of national and local policies-a Dutch perspective. Environment and Planning. B 22, 721-737.

Pucher, J. (1997). Bicycling boom in Germany: a revival engineered by public policy. Transportation Quarterly. $51(4), 31-46$.

Pucher, J., Dijkstra, L. (2000). Making walking and cycling safer: lessons from Europe. Transportation Quarterly. 54 (3), 25-50.

Pucher, J., Komanoff, C., Schimeck, P. (1999). Bicycling renaissance in North America? Recent trends and alternative policies to promote bicycling. Transportation Research A. 33, 625-654.

Richardson, B. (1999). Towards a policy on a sustainable transportation system. Transportation Research Record. 1670, 27-34.

Shoup, D. (1997). The high cost of free parking. Journal of Planning Education and Research. 17 (1), 3-20.

Taylor, D., Davis, W. (1999). Review of basic research in bicycle traffic science, traffic operations, and facility design. Transportation Research Record. 1674, 102-110.

Tolley, R. (1996). Green campuses: cutting the environmental cost of commuting. Journal of Transport Geography. 4 (3), 213-217.

Tolley, R. (Ed.) (1997). The Greening of Urban Transport, Planning for Walking and Cycling in Western Cities, 2nd ed, Wiley, New York.

USDOT. (1994). The National Bicycling and Walking Study_Transportation Choices for a Changing America, Author, Washington, DC.

Weerts, D. (1992). Bicycling and the university-a fertile combination for the nurturing of bicycle-friendly communities. In: Boivin, R., Pronovost, J. (Eds.), The Bicycle: Global Perspectives, Velo Quebec Publications, Montreal.

Weerts, D. (1998). Evolution of a Cyclist-Friendly Community-The Davis. Model. Paper presented at the ProBike/ProWalk conference-Santa Barbara. [Online] available: http://www.taps.ucdavis.edu/.

Wilkinson, B. (1997). Nonmotorized transportation: the forgotten modes. Annals of the American Academy of Political and Social Sciences. 553, 87-93.

Table 1. Contextual information about the selected cases

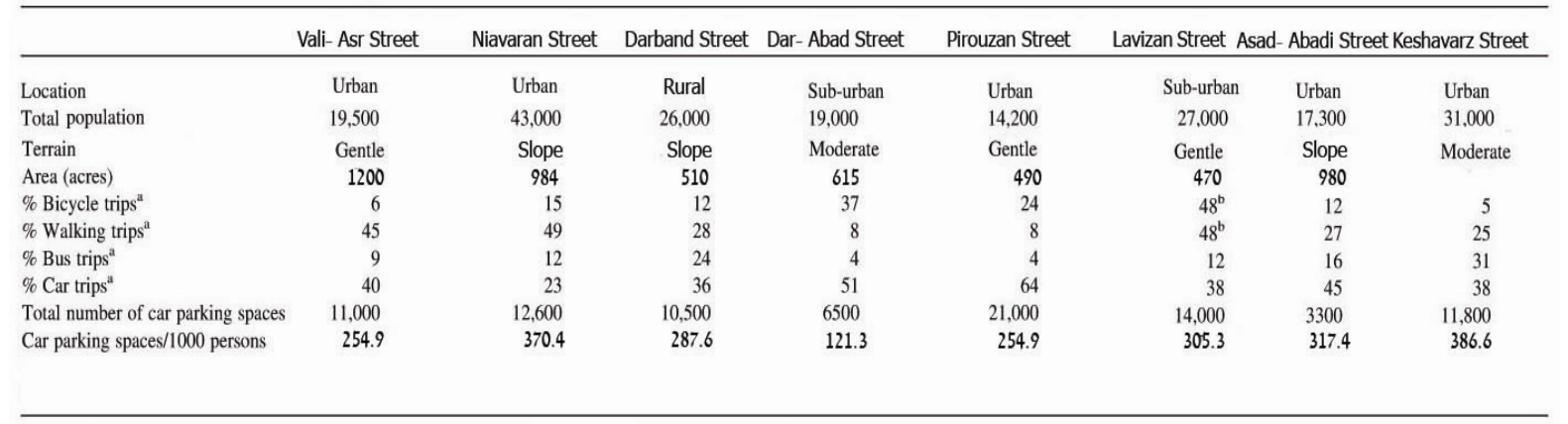

Table 2. Organizational aspects regarding no motorized transportation sources

\begin{tabular}{|c|c|c|c|c|c|c|c|c|}
\hline & Vali-Asr St & Niavaran St & Darband St & Dar-Abad St & Pirouzan St & Lavizan S & Asad-Abadi St & KeshavarzSt \\
\hline Bicycle/pedestrian committee & $\nu$ & & 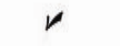 & $\boldsymbol{\nu}$ & $\boldsymbol{\nu}$ & 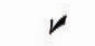 & $\nu$ & $\boldsymbol{\nu}$ \\
\hline Full time coordinator & & $\nu$ & & $\boldsymbol{\nu}$ & $\boldsymbol{v}$ & $\boldsymbol{\nu}$ & $\checkmark$ & \\
\hline Conduct regular user surveys & & $\nu$ & $\boldsymbol{\nu}$ & & $\boldsymbol{\nu}$ & & & \\
\hline Identify major funding sources & & $\boldsymbol{r}$ & $\nu$ & $\boldsymbol{r}$ & & $\boldsymbol{r}$ & & $\boldsymbol{r}$ \\
\hline Communicate bicycle and pedestrian planning knowledge & $r$ & $\boldsymbol{v}$ & & $\boldsymbol{v}$ & $\boldsymbol{v}$ & & & $\boldsymbol{v}$ \\
\hline
\end{tabular}


Table 3. Planning aspects regarding no motorized transportation sources

\begin{tabular}{|c|c|c|c|c|c|c|c|c|}
\hline & Vali-Asr St & Niavaran St & Darband St & Dar-Abad St & Pirouzan St & Lavizan St & Asad-Abadi St & t KeshavarzSt \\
\hline Bicycle/pedestrian plan & & & & $\nu$ & & & $\nu$ & \\
\hline Changes to existing policies & $\boldsymbol{v}$ & $\nu$ & $\nu$ & & $\nu$ & $\boldsymbol{v}$ & $\nu$ & $\nu$ \\
\hline Integrate nonmotorized uses into campus transportation plannir & & & & $\boldsymbol{v}$ & $\nu$ & & $\boldsymbol{v}$ & $\nu$ \\
\hline Campus-wide nonmotorized urban design guidelines & $\boldsymbol{v}$ & & $\nu$ & & & & & \\
\hline Reserved corridors/greenways & & $\nu$ & $\nu$ & $\nu$ & & 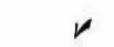 & & $\nu$ \\
\hline
\end{tabular}

Table 4. Bicycle and pedestrian facilities sources

\begin{tabular}{|c|c|c|c|c|c|c|c|c|}
\hline & Vali-Asr St & Niavaran St & Darband St & Dar-Abad St & Pirouzan St & Lavizan St & Asad-Abadi St & Keshavarz St \\
\hline Bicycle paths (miles) & 4 & 2.5 & 3 & 3 & 1 & 1.5 & 3 & 4.5 \\
\hline Bicycle lanes (miles) & 2 & 3 & 1 & 1 & $\mathrm{n} / \mathrm{a}$ & 12 & $\mathrm{n} / \mathrm{a}$ & 1 \\
\hline Bicycle routes & & $\boldsymbol{r}$ & $\boldsymbol{\nu}$ & & $\boldsymbol{\nu}$ & $\boldsymbol{r}$ & $\boldsymbol{r}$ & $\boldsymbol{r}$ \\
\hline Dismount zones & $\boldsymbol{\nu}$ & & $\boldsymbol{\nu}$ & $\boldsymbol{\nu}$ & $\boldsymbol{\nu}$ & $\boldsymbol{\nu}$ & $\boldsymbol{\nu}$ & $\boldsymbol{\nu}$ \\
\hline Bicycle spaces at parking racks & & 1250 & 7300 & 9600 & 12,000 & 15,000 & 4700 & 6100 \\
\hline Bicycle spaces $/ 1000$ people & $\mathrm{n} / \mathrm{a}$ & 186.4 & 315.5 & 329.9 & 526.3 & 405.4 & 226.0 & 124.0 \\
\hline Number of bicycle lockers & & 30 & 14 & 18 & 100 & 36 & 15 & 50 \\
\hline Other parking structures & & & & & $\nu$ & $\boldsymbol{\nu}$ & $\boldsymbol{\nu}$ & \\
\hline (Re) Designed intersections and crossings & & $\boldsymbol{\nu}$ & $\nu$ & $\nu$ & $\nu$ & & & $\nu$ \\
\hline Traffic - calming measures & & & & & $\nu$ & $\nu$ & & $\nu$ \\
\hline Signing and markings & $\nu$ & & $\nu$ & $\nu$ & & $\nu$ & $\nu$ & \\
\hline Showers - changing rooms & & & & & $\boldsymbol{r}$ & & & \\
\hline
\end{tabular}

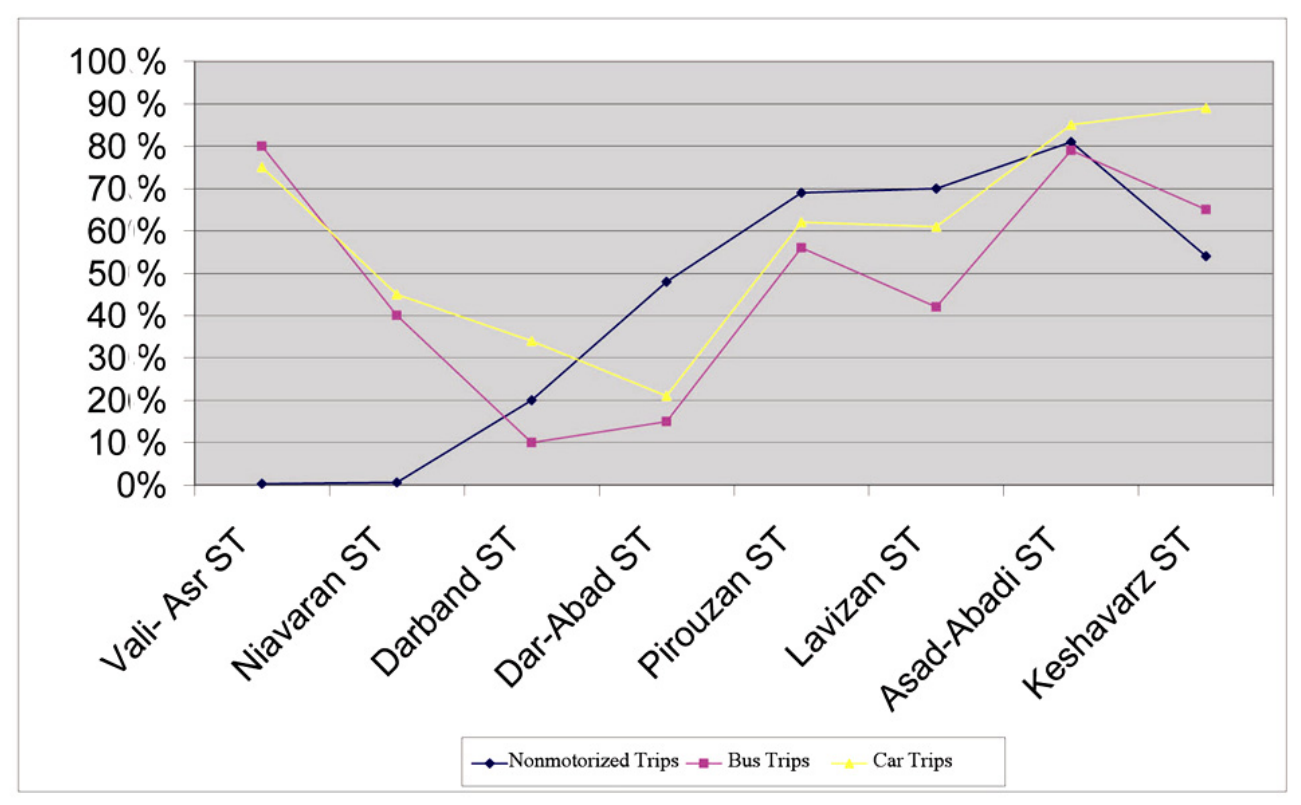

Figure 1. Comparison of modal shares for the eight cases 


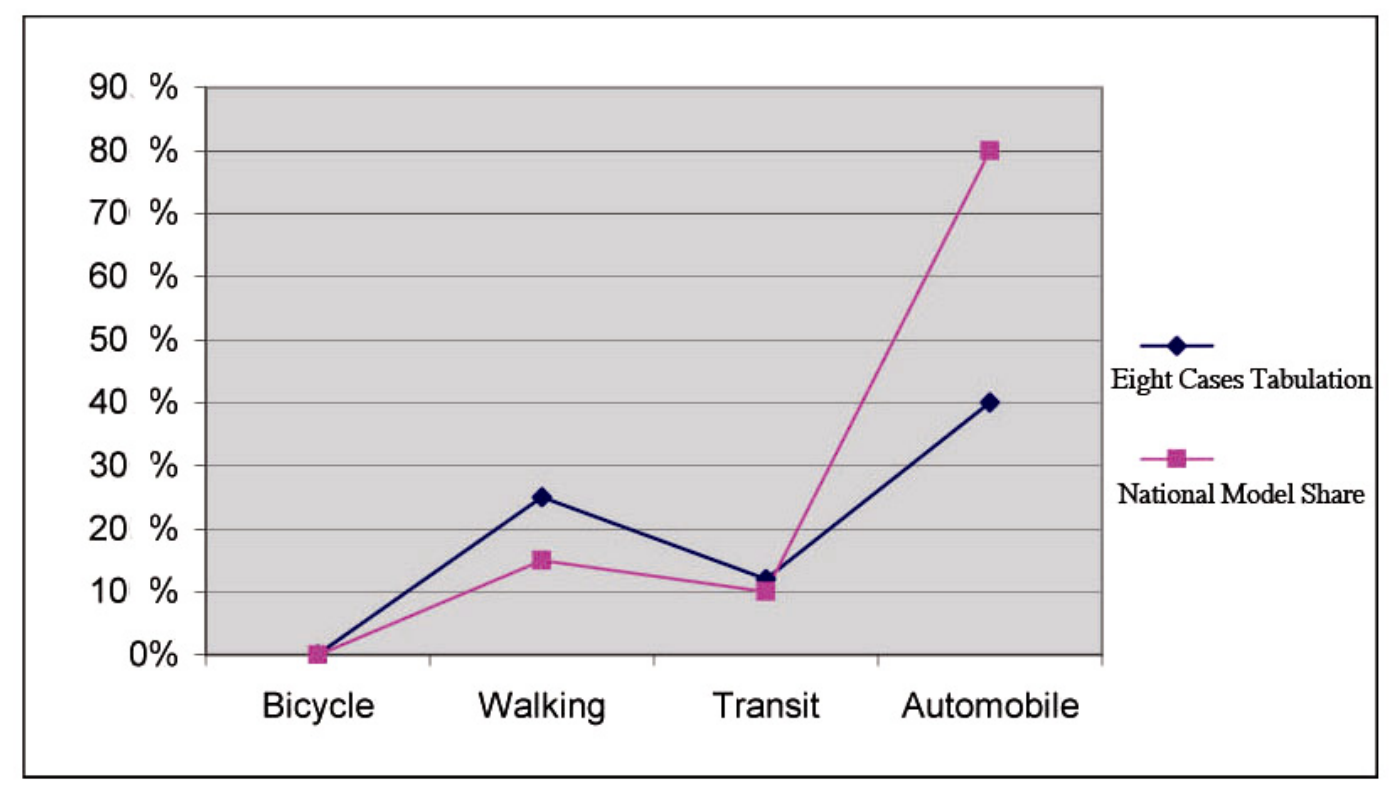

Figure 2. Comparison of 2009 national modal share with an average for the eight cases 